\title{
Characterizing Phase Transformations and Their Effects on Ferritic Weld Residual Stresses with X-rays and Neutrons
}

\author{
H. Dai ${ }^{1}$, J.A. Francis ${ }^{1}$, H.J. Stone ${ }^{2}$, H.K.D.H. Bhadeshia ${ }^{2}$ and P.J. Withers ${ }^{1, a}$ \\ ${ }^{1}$ School of Materials, University of Manchester, Grosvenor Street, Manchester M1 7HS, UK \\ ${ }^{2}$ Materials Science \& Metallurgy, University of Cambridge, Pembroke St, Cambridge, CB2 3QZ, UK \\ aphilip.withers@manchester.ac.uk
}

Keywords: bainite, martensite, neutron diffraction, phase transformation, residual stress, synchrotron X-ray diffraction.

\begin{abstract}
Weld residual stresses often approach, or exceed, the yield strength of the material, with serious implications for the integrity of engineering structures. It is not always feasible to measure residual stresses, so integrity assessments often rely heavily on numerical models. In ferritic steels, the credibility of such models depends on their ability to account for solid-state phase transformations that can have a controlling effect on the final residual stress state. Furthermore, a better understanding of weld transformations provides an opportunity to engineer the weld stress state and microstructure for improved life. In this paper the complementary merits of synchrotron X-ray and neutron diffraction are exploited both to verify and refine weld models and to inspire the development of weld filler metals to control weld stresses. In terms of weld filler metal design, Xray diffraction is used to characterize phase transformations in real time during realistic weld cooling cycles, for understanding small-scale behaviour, and identifying features that need to be incorporated into finite-element models. Meanwhile, neutron diffraction is used to elucidate the practical consequences of solid-state phase transformations on the macroscopic scale, thereby providing crucial validatory structural integrity data.
\end{abstract}

\section{Introduction}

Near yield tensile residual stresses are commonly encountered in welded components. These may compromise structural integrity through reduced fatigue life or increased susceptibility to environmentally assisted failure mechanisms [1]. Life-limiting residual stresses can sometimes be reduced by post weld heat treatment (PWHT), but this may be impractical with large or inaccessible components such as those, for example, used in the construction of power plants or submersibles.

The complex interplay between the sharp thermal gradients and the transient thermomechanical properties of the alloy can profoundly influence the final state of stress. Furthermore, strains arising from phase transformations can drastically affect the picture, giving localized stress relaxation and local material properties which are hard to predict a priori. Displacive transformations, in particular, such as bainite or martensite are associated with shape deformations characterized as invariant-plane strains with large shear components in addition to dilatation normal to the invariant plane. The volume expansion due to transformation upon cooling is normally advantageous in reducing the effect of constrained thermal contraction as the weld zone cools. The large shear strain manifests on a macroscopic scale when the microstructure becomes non-random, i.e., when certain crystallographic variants are favoured during phase transformation upon cooling. By engineering the temperature regime over which phase changes occur, the volume and shear strains may be exploited to mitigate the development of residual stresses. The work by Jones and Alberry [2, 3] suggests that tensile residual stresses are best avoided by suppressing the transformation temperature such that the phase change can continue to compensate for the accumulation of contraction strains down to ambient temperature. Indeed, recent work in Japan, using welding 
consumables with low transformation temperatures has shown that it is possible not only to reduce the residual tensile stresses, but to introduce residual compression into the weld region, with consequential increases in fatigue life [4]. Unfortunately, those welding alloys lack toughness.

Almost from its inception as a bulk strain measurement technique, neutron diffraction has been used to map the residual stresses deep inside welded joints [5]. However, where solid state transformations occur during the welding process it can be difficult to ascertain how the stress distribution evolved solely from an examination of the final weld. It may be important to see how stresses change during weld cooling to optimise the interplay between transformation strains and thermal contraction. One approach is to exploit the fast data acquisition times obtainable with synchrotron diffraction to study the stress and phase distributions around the weld pool under the transient temperature conditions experienced during welding. Elmer et al. [6-8] were probably the first to undertake welding trials in situ on a synchrotron diffractometer table. Whilst these studies have successfully characterized the phase distribution, uncertainties in the temperature at the observation location due to steep transient thermal gradients make it difficult to determine unambiguously the effect of the thermomechanical conditions on the material response and on the phases that form.

As residual stresses form principally in the solid state during cooling from elevated temperatures, an alternative approach is to neglect weld solidification and to focus on the material response to controlled thermomechanical cycles. It then becomes feasible to separate the contributions of stress, temperature and composition. By using in situ synchrotron X-ray diffraction, it is possible to acquire crystallographic, textural and stress information together with a wealth of other data as a function of time and temperature under controlled cooling cycles representative of expected weld cooling histories. This is in contrast to dilatometry and fast DSC, which provide only indirect data.

We use here a combination of experiment and numerical modelling to study the effects of transformation temperature on the accumulation of stress during the cooling of constrained samples. This is achieved by comparing the use of a new martensitic weld filler metal LTTE proposed by Wang et al. [9], which was designed to have a low transformation temperature, with an existing filler metal (OK75.78) having a mixed bainite and martensite microstructure and a transformation temperature of about $410^{\circ} \mathrm{C}[10]$.

\section{Experimental Description}

\section{Weld filler metals:}

Two weld fillers have been studied. The first, OK75.78, begins transformation at about $410^{\circ} \mathrm{C}$. The second is fully martensitic with a transformation-start temperature around $280^{\circ} \mathrm{C}$. The compositions of the two alloys are given in Table 1.

\section{Test-welds}

Two plates $(375 \times 200 \times 12 \mathrm{~mm})$ were prepared from the high strength steel, Weldox 960 (Table 1). A $5 \mathrm{~mm}$ deep ' $\mathrm{V}$ '-groove was machined along the centre of each plate, with an included angle of $60^{\circ}$, into which a single weld bead of either OK75.78 or LTTE was deposited using manual-metal arc welding. The details of the welding conditions have been described elsewhere [10], but in essence the welding was undertaken in the down-hand position with a heat input between 2.2 and $2.5 \mathrm{~kJ} \mathrm{~mm}^{-1}$, while a preheat temperature of $125^{\circ} \mathrm{C}$ was used and the plates were restrained by clamping during welding.

\section{Weld cooling simulations}

An Instron/NPL electro-thermal mechanical testing (ETMT) rig was used to simulate thermomechanical conditions typical of those experienced during welding. This comprised a $4 \mathrm{kN}$ screw driven mechanical testing stage, with thermal cycles being achieved by Ohmic heating due to 
a direct current applied across the sample under feedback control from a type- $\mathrm{R}$ thermocouple attached to the centre of the sample. Heating and cooling rates of up to $100^{\circ} \mathrm{C} \mathrm{s}^{-1}$ may be readily achieved, with mechanical loads being superimposed, if required. Samples having a 1-2 mm square or rectangular section and a length of the order of $40 \mathrm{~mm}$ can be accommodated. The simple geometry of these samples ensures that testing costs are kept to a minimum, whilst the thickness is also ideally suited to diffraction measurements conducted in transmission with hard X-rays at synchrotron facilities. For our experiments the ETMT was mounted on the ID11 beam-line at the European Synchrotron Radiation Facility (ESRF) in Grenoble, France (Figure 2). 1.5 × 1.5 $\times 40 \mathrm{~mm}$ coupons were cut from an undiluted all-weld-metal sample prepared using the OK 75.78 filler.

To limit the effects of temperature gradients due to the parabolic temperature distribution generated along the length of the coupon, slits positioned in the incident beam path were used to define a $400 \mu \mathrm{m}$ wide diffraction gauge volume at the centre of the sample. A variation of no more than $2^{\circ} \mathrm{C}$ is anticipated over such a volume at a temperature of $900^{\circ} \mathrm{C}$. To ensure correspondence between the temperature measured by the thermocouple and that of the gauge volume, the test rig was translated across the beam until the centre of the thermocouple bead could be identified from the observed diffraction patterns. The sample was then translated vertically such that the diffraction gauge volume was immersed in the sample, directly below the centre of the thermocouple bead, at a point at which no further diffraction signal was detected from the thermocouple bead.

A photon energy of $80 \mathrm{keV}(0.1555 \AA)$ was selected using a double Si $\{111\}$ monochromator. Diffraction data were acquired with a FReLoN (Fast-Readout Low-Noise) camera system having $2048 \times 2048$ pixels, each corresponding to $46.8 \times 48.0 \mu \mathrm{m}$, mounted approximately $258 \mathrm{~mm}$ downstream of the sample with its centre aligned with the transmitted beam. To increase data acquisition rates, and to enable diffraction images to be acquired at a sufficient rate to allow the phase transformations to be adequately characterized at the highest cooling rates, only the central half of the CCD was used. In addition, the data were binned in 4 pixel blocks in the vertical direction. This enabled images of the Debye-Scherrer rings to be acquired with exposures as short as $30 \mathrm{~ms}$ at approximately $30 \mathrm{~Hz}$. Calibration of the sample-detector distance, the position of the straight-through beam and the tilt of the detector were made through measurements of the diffraction pattern obtained from a $\mathrm{LaB}_{6}$ standard sample of known lattice parameter, which was placed in the sample position in the ETMT. Additionally, to eliminate the contribution from the background signal, exposures in the absence of the beam were subtracted from the acquired diffraction images.

To assess the effects of cooling rate on the phase transformations, the samples were subjected to thermal cycles comprising: heating to $850^{\circ} \mathrm{C}$ at $10^{\circ} \mathrm{C} \mathrm{s}^{-1}$, an isothermal dwell for $60 \mathrm{~s}$ at $850^{\circ} \mathrm{C}$, followed by continuous cooling to room temperature at cooling rates of $100,90,80,70,60,50,40$, $30,20,10,5,2,1,0.5,0.2$ and $0.1{ }^{\circ} \mathrm{C} \mathrm{s}^{-1}$. The mechanical stage was run under load control with a set-point of zero load. This permitted free thermal expansion and contraction of the samples throughout the thermal cycles.

Processing of the raw diffraction images was performed using the Fit2D image processing software, including corrections for the spatial distortion and detector efficiency along with subtraction of the background signal [11]. The images were then integrated within $20^{\circ}$ on either side of the horizontal to obtain one-dimensional intensity versus $2 \theta$ data sets. A plot of intensity versus $2 \theta$ data acquired from the experiment conducted with a cooling rate of $10^{\circ} \mathrm{C} / \mathrm{s}$ is given in Figure 3.

To obtain the results presented in Figure 3, Rietveld refinement of the one-dimensional diffraction data were performed using the General Structure Analysis System (GSAS) package [12]. The structures of ferrite $(\mathrm{Im} 3 \mathrm{~m})$ and austenite $(\mathrm{Fm} 3 \mathrm{~m})$ were fitted with the phase fractions, and lattice parameters were permitted to vary. The background was approximated using a 4-term shifted Chebyshev polynomial. Note that the term ferrite here covers both bainite and martensite because in the alloys considered, the weld metals have low carbon concentrations so that both of these phases retain cubic symmetry. 


\section{Results}

\section{Macroscopic Residual Stresses}

Macroscopic residual stress measurements were made at the Chalk River facility as described elsewhere [10]. Once mapped and the elastic strains converted to stress, the latter were averaged using a mirroring technique. That is to say that symmetry was assumed about the weld centerline (this was supported by the actual point to point measurements), and each calculated stress was averaged with the value at the corresponding mirror image location about the weld centerline. The results in Figure 4 correspond to averaged values.

In the weld made with OK75.78, both the weld nugget and the underlying reaustenitised HAZ were expected to transform at high temperatures (Fig. 4 and 7). The level of stress both in the weld nugget and underlying region is low but the tensile stress increases with distance along the horizontal axis, with peak stresses of about $800 \mathrm{MPa}$ located at about half the depth and at the outer boundary of the HAZ. The domain in which the stress is greater than $600 \mathrm{MPa}$ is large, having a width of just under $5 \mathrm{~mm}$ parallel to the horizontal axis.

The residual stress field for the LTTE weld is quite different (Fig. 4 and 7). Most marked is the significantly compressive stress within the weld nugget. It is clear from Fig. 7 that the stress contours within the HAZ closely follow the shape of the nugget, i.e., steeply inclined stress contours which are a stark contrast to those in OK75.78. The phase change within the nugget has resulted in a large reduction of the tensile stresses within the adjacent HAZ up to the depth of $5 \mathrm{~mm}$. The peak tensile stresses are much smaller than in OK75.78 and the regions within which they occur are also smaller.

Beneath the LTTE weld nugget, in the parent plate material, the phase change occurs at a higher temperature than for the nugget itself. It is therefore possible for tensile stresses to arise there. To a certain degree, the interpretation of the stress distributions in these regions is complicated by the fact that the residual stresses must balance over the weld section. Thus, in these regions it is possible that the stresses may not be explained solely in terms of the local transformation temperature.

When the residual stresses over all depths are considered, it is evident that the LTTE filler has been effective in reducing the build up of tensile stress within the nugget and, to a lesser extent, in the peak stress region near the HAZ boundary. It is also likely that the observed compensation would have been greater and more uniform if full penetration welds had been made.

\section{Weld filler metal response}

In order to rationalize the observed macro residual stresses it is important to follow the evolution of phase fractions during weld cooling. The phase fractions as a function of temperature, under zero applied load, at cooling rates of $100,10,1 \& 0.1{ }^{\circ} \mathrm{C} \mathrm{s}^{-1}$ are given in Fig. 5 from the synchrotron measurements. The fraction of ferrite evolves in an approximately sigmoidal manner during cooling. The temperature at which ferrite first appears is suppressed as the cooling rate increases. The driving force becomes greater if the transformation is suppressed, so the initial rate of austenite decomposition is greater at higher cooling rates. As a consequence, the majority of the transformation occurs over a narrower temperature range at higher cooling rates. Notice that the diffraction method does not permit the detailed nature of the ferritic phase (allotriomorphic ferrite, Widmanstätten ferrite, bainite or martensite) to be determined.

\section{Satoh Tests}

The effects of the phase transformation and the associated volume and shear strains on the development of stresses during constrained cooling are well illustrated by the Satoh test results given in Fig. 6. These show the stresses that develop as a constrained bar is cooled from its austenitic state. The form of these curves is explained elsewhere [10], but in essence, the bar shrinks as it cools, causing tension to develop, first at a rate determined by the coefficient of expansion of the austenite, then by the yield locus as a function of temperature. As the 
transformation takes place the transformation strains, as well as any associated transformation plasticity, act to reduce the tensile strains which can even reverse sign. Once transformation is complete (c.f. Fig. 5), the bar continues to shrink, with the result that tensile stresses are introduced at a rate that is determined by the expansion coefficient of the ferrite. As is evident by comparing LTTE and OK75.78, the lower the transformation temperature, the less tensile is the final constrained weld stress.

\section{Finite Element Modelling}

Given the complexity of the physical processes that are taking place within welded joints, it is instructive to assess the accuracy with which residual stresses can be predicted on the basis of the transformation behaviour. To this end, numerical models were created for the groove welds made using the SYSWELD finite element software. SYSWELD accounts for many of the features of phase transformations in steels, such as the dilatational component of the transformation strain, and phase-and temperature-dependent material properties. In this work, prior to running SYSWELD models, the transformation temperatures of the parent steel and weld metals were estimated according to software available via the Materials Algorithm Project [13], for which the underlying principles have been reported elsewhere [14-16]. Estimates for the elevated-temperature yield stress of each weld metal were obtained by examining the results of the Satoh tests and assuming that once the stress level had reached yield, and prior to the commencement of a transformation, the stress that is recorded in a Satoh test can be assumed to be representative of the yield locus. A room-temperature value for the yield stress of the parent material was obtained from the manufacturer's data sheets. At intermediate temperatures, values for the yield stress were either interpolated or extrapolated.

For each weld, a transient 3-dimensional analysis was carried out. Complex arc and weld pool phenomena were not considered, as is generally the case for the numerical prediction of weld residual stresses [1, 17]. However, a double-ellipsoid heat source was used to represent the welding arc [18], and this was calibrated using the in-built heat-source fitting tool within SYSWELD, by comparing the predicted geometry of the fusion zones and HAZ's with those measured from a macrograph section through each welded plate. In each case, a 3-dimensional simulation was carried out using 48,240 eight-noded brick elements in both the transient-thermal and mechanical analyses. In order to account for the effects of annealing the history of any element, including any plastic strain, was erased if the peak temperature exceeded the temperature of fusion. Otherwise, the model was configured to simulate the welding conditions as accurately as possible. Details of the welding conditions for these plates have been reported previously [10].

A comparison of the longitudinal residual stress distributions predicted by SYSWELD with those that were measured by neutron diffraction summarized here and reported in [10] is given in Figure 7. The neutron diffraction results (top) show that, when compared to OK75.78, the LTTE weld metal introduces significant compressive residual longitudinal stresses within the fusion zone. As discussed above, this is consistent with LTTE having a lower transformation temperature than OK75.78. Furthermore, the peak tensile residual stresses, which for both welds appear to arise just outside the HAZ, are somewhat lower in the weld made with LTTE, and they arise over a smaller region. In the weld made with the OK75.78 filler material, the phase transformations that have taken place within the HAZ and fusion zone still have significantly reduced the residual stresses to levels that are below the peak tensile stresses found immediately outside the HAZ. Since the transformation temperatures of the weld metal and parent material are similar in this case (Weldox transforms at around $460^{\circ} \mathrm{C}$ compared to $440^{\circ} \mathrm{C}$ for diluted $\mathrm{OK} 75.78$ [10]), these zones appear to behave similarly, and there is no discernible variation in residual stress with distance down the weld centre-line.

It is evident from Fig. 7 that the major features of the stress distributions have been predicted correctly for both filler metals. For example, it appears that the location of the peak tensile stresses is approximately correct in each case. Furthermore, the models have predicted that the OK75.78 filler metal will lead to relatively low stresses within and directly underneath the weld bead, and 
that the LTTE filler metal introduces highly compressive residual stresses to the weld metal region of about the right level $(\sim-400 \mathrm{MPa})$. The magnitude of the tensile peak stresses, however, appears to be somewhat over-estimated by the SYSWELD models. This may be related to the limitations associated with using data from Satoh tests to estimate the yield locus. In both cases, isotropic hardening was assumed, but the authors also created models that assumed kinematic hardening and it was found that, for the single welding thermal cycle, there did not appear to be any notable sensitivity to the hardening model adopted.

Interestingly, SYSWELD predicts that the transformation temperature of the weld metal does not have a significant effect on the magnitude of the peak stresses beyond the HAZ, although a small reduction in the extent of the peak-stress region does appear to have been captured. It is possible, however, that the effects of the weld metal transformation temperature would have been predicted more accurately if the transformation strains within the fusion zone and HAZ had been represented faithfully. In this respect it should also be noted that variant selection has not been incorporated in the SYSWELD model. This means that only the volume part of the transformation has been accounted for. The anisotropic shear component may be significant, especially for transformations at low temperature where the stress just prior to transformation will be large (see Fig. 6) and thus may bias variant selection. This would increase the effectiveness of the transformation in reducing the residual stress. This effect will be reported subsequently.

While the overall agreement between the simple SYSWELD model trained only on the basis of Satoh tests and the neutron results is encouraging, the discrepancies between the models and the neutron diffraction measurements highlight the need for validation and improved understanding of the transformation behaviour. In this respect further in-situ synchrotron X-ray diffraction experimentation offers many advantages and insights.

\section{Discussion}

The dramatically different responses of OK75.78 and LTTE in Figure 6 illustrate the importance of having accurate information in relation to the transformation temperatures of steels and weld metals if numerical models for residual stresses in welds are to be viable. Such information is usually presented in the form of CCT diagrams and forms necessary input data for any finite element model that endeavours to account for the effects of phase transformations on weld residual stresses.

It is worth noting that models for the prediction of CCT diagrams are available in the literature $[14,19]$. However, these models are generally most reliable when the steel composition falls within certain limits, and they are often dependent on having reliable estimates for the austenite grain size prior to the commencement of a phase transformation. It is also worth pointing out that it is difficult to find any models in the literature that quantify the sensitivity of CCT diagrams to the stresses that reside within the material during cooling, and in welds these stresses can be large. In this respect, in-situ X-ray diffraction has a critical role to play in characterizing the phase transformation behaviour of steels.

Indeed, another issue that arises in the modelling of residual stresses in steel welds is that much of the published CCT data that were used in the development of kinetic models were obtained by dilatometry, using coupons with a larger cross-section than was the case for the in-situ experiments described this article [20]. Furthermore, the austenitisation times for these data are often more typical of those used in the heat treatment of a plate material than they are of austenitisation in the heat-affected zone (HAZ) of a welded joint [21]. However, in-situ X-ray diffraction experiments such as those described here are well suited to handle smaller test coupons and thermal cycles that are more closely aligned with welding processes, so that CCT diagrams obtained in this way are likely to be more useful in welding simulations [22].

Perhaps the most compelling argument for the employment of in-situ X-ray techniques is that they also offer the potential to quantify the contributions to the transformation strain in the event of a displacive phase transformation. For example, biases in the selection of crystallographic variants that occur when bainitic or martensitic transformations take place under the influence of stress can 
be detected by observing the variation in the intensity of the diffracted beam over the full $360^{\circ}$ of a Debye-Scherrer ring. If there were to be little or no bias in the selection of crystallographic variants, then the variation in the intensity of the diffracted beam around a ring might not be expected to be large. On the other hand, significant variant selection may lead to noticeable peaks and troughs in intensity.

The nature of the transformation strain, and the contribution of the dilatational and shear components, is of particular interest in the context of Figure 6. It can be seen that the effect of the transformation strain in reducing the stress within the test coupon is larger for LTTE than it is for OK75.78. While it is possible to argue that the volume change is larger at the lower transformation temperature, it is also likely that the relative contributions of the dilatational and shear components to the total transformation strain have altered. The LTTE coupon had clearly accumulated a larger contraction stress prior to the onset of the martensitic transformation. This is likely to have resulted in a greater bias in the orientation of martensite plates and, as a result, the shear components of the transformation strain may have contributed to a more anisotropic volume change that complied to a greater extent with the accumulated contraction stress. Given that ideal variant selection for a displacive transformation in steels is believed to correspond to a monotonic strain of approximately $15 \%$ [23], much larger macroscopic transformation strains become feasible. Unfortunately, a detailed analysis of the extent to which variant selection has occurred in the case of the two alloys that are discussed in this study is beyond the scope of this article. Work, however, is ongoing and will be reported in a subsequent paper.

It should also be borne in mind that in the present work we have considered only a single weld pass. The occurrence of retransformation of previously laid down beads will further complicate the analysis. This will be especially important for welds laid down using low transformation temperature weld metal because of the enhanced opportunity for repeated transformation.

\section{Conclusions}

1. Neutron diffraction measurements [10] have shown significant differences between the residual stresses in welds based on high and low transformation temperatures.

2. We have demonstrated that thermo-mechanical simulation combined with fast synchrotron Xray diffraction allows the characterization of the phases under conditions representative of those encountered in welding. The advantages of using a thermomechanical simulator include that the conditions can be very carefully controlled and that the thermal history at each location is well known. The technique was used successfully to determine the cooling rate dependence of phase transformations in the weld filler alloy OK75.78.

3. The data that can be acquired with in-situ X-ray diffraction include the temporal and thermal evolution of phase fractions, preferred orientation, lattice parameters and, potentially, residual stresses as a function of both cooling rate and applied mechanical constraint.

4. The data may be used both to rationalize the development of residual stresses during welding and to provide the basis for incorporating the major features of phase transformations into finite-element models for weld residual stresses.

5. Neutron diffraction measurements also have a vital role to play in validating numerical models for weld residual stresses. In this respect current numerical models tend to include only the volume change associated with the transformation. Further neutron work combined with microstructural analysis by EBSD will help to resolve the degree of complexity required to more completely model the weld stress state.

Finally the current study has focused on LTTE. We are currently researching into other low transformation temperature filler metals that may be able to reduce residual stress whilst at the same time maintaining weld fracture toughness.

\section{Acknowledgements}


We acknowledge Dr. L. Karlsson of ESAB AB for the provision of weld filler materials. Part of this work was undertaken when HJS was a Research Fellow at the University of Manchester funded by EPSRC and Rolls-Royce Marine. The provision of synchrotron beam time by Chalk River and the ESRF and the help of Drs Ron Rogge, Matthew Peel, Gavin Vaughan, Jonathan Wright, Magnus Bostrom and Andrew Gotz in undertaking the experiments are gratefully acknowledged; the ETMT was made available through Fame38. Finally, HD and JAF would like to acknowledge support from Rolls-Royce Marine.

\section{References}

[1]. J. A. Francis, H. K. D. H. Bhadeshia and P. J. Withers, "Welding Residual Stresses in Ferritic Power Plant Steels", Materials Science and Technology, 23 (9), 1009-1020, 2007.

[2]. W. K. C. Jones, P. J. Alberry, "Ferritic Steels for Fast Reactor Steam Generators", (British Nuclear Engineering Society, London, 1-4, 1977).

[3]. W. K. C. Jones, P. J. Alberry, Residual Stresses in Welded Construction and their Effects, London (1977), $15-26$.

[4]. J. Yamamoto, Y. Muramatsu, S. Zenitani, N. Hayakawa, and K. Hiraoka: Control of Welding Residual Stress by Low-Temperature Transformation Welding Consumables - Influence of restraint of joint and transformationtemperature on residual stress, in Proceedings of 6th International Conference on Trends in Welding Research, 2002: ASM International: p. 902-905

[5]. D. J. Smith, R. H. Leggatt, G. A. Webster, H. J. Macgillivray, P. J. Webster, G. Mills: Journal of Strain Analysis for Engineering Design, 23, (Oct, 1988), 201-11.

[6]. J. W. Elmer, J. Wong, T. Ressler: Scripta Mater. 43 (2000), 751-7.

[7]. S. S. Babu, J. W. Elmer, S. A. David, M. A. Quintana.: Proc. R. Soc. Lond., 458A (2001), 811-21.

[8]. J. W. Elmer, T. A. Palmer: Metallurgical and Materials Transactions a-Physical Metallurgy and Materials Science 37A (Jul, 2006), 2171-82.

[9]. W.X. Wang, L.X. Huo, Y.F. Zhang, D.P Wang and H.Y. Jing: "New developed welding electrode for improving the fatigue strength of welded joints", Journal of Materials Science \& Technology, 18 (6), 527-531, 2002.

[10]. J. A. Francis, H. J. Stone, S. Kundu, R. B. Rogge, H.K.D.H. Bhadeshia, P. J. Withers and L. Karlsson: "The Effects of Weld Metal Transformation Temperature on Residual Stresses in Ferritic Steels", In Review, Journal of Pressure Vessel Technology.

[11]. A. P. Hammersley, S. O. Svensson, M. Hanfland, A. N. Fitch, D. Hausermann: High Pressure Research, 14, 1996, 235-48.

[12]. A. C. Larson, R. B. Von Dreele, "GSAS: Generalized Structure Analysis System”, Los Alamos National Laboratory, 1985.

[13]. www.msm.cam.ac.uk/map/steel/programs/MTTT DATA.html\#down

[14]. H.K.D.H. Bhadeshia: "“Thermodynamic Analysis of Isothermal Transformation Diagrams”, Metal Science, 16, $159-165,1982$

[15]. H.K.D.H. Bhadeshia: “A Rationalisation of Shear Transformations in Steels”, Acta Metallurgica, 29, 1117-1130, 1981.

[16]. S. M. Hodson: "MTDATA-Metallurgical and Thermochemical Databank", National Physical Laboratory, Teddington, UK, 1989.

[17]. H.J. Stone, S.M. Roberts and R.C. Reed, "A Process Model for the Distortion Induced by the Electron-Beam Welding of a Nickel-Based Superalloy", Metallurgical and Materials Transactions A - Physical Metallurgy and Materials Science, 31 (9), 2261-2273, 2000.

[18]. J. Goldak, A. Chakravarti and M. Bibby "A new finite element model for welding heat sources", Metallurgical and Materials Transactions B, 15 (6), 299-305, 1984.

[19]. M.V. Li, D.V. Niebuhr, L.L. Meekisho and D.G. Atteridge: "A Computational Model for the Prediction of Steel Hardenability”, Metallurgical and Materials Transactions B - Process Metallurgy And Materials Processing Science, 29 (3), 661-672, 1998.

[20]. G.F. Vander Voort, "Atlas of Time-Temperature Diagrams for Irons and Steels", ASM International, 1991.

[21]. M. Maalekian, M.L. Lendinez, E. Kozeschnik, H.P. Brantner and H. Cerjak: "The Influence of Peak Temperature and Deformation on Welding CCT Diagram of Eutectoid Carbon Steel”, Advanced Materials Research, 15-17, 1008-1013, 2007.

[22]. H.J. Stone, H.K.D.H. Bhadeshia and P.J. Withers: "In-Situ Monitoring of Weld Transformations to Control Weld Residual Stresses, in proceedings of MECA SENS IV - Conference on Stress Evaluation, Vienna, Austria, September 24-26, 2007.

[23]. H.K.D.H. Bhadeshia, ISIJ International, 42, 1059-1060, 2002. 
Metallurgical and Materials Transactions A, Vol. 39A, 2008, 3070-3078 

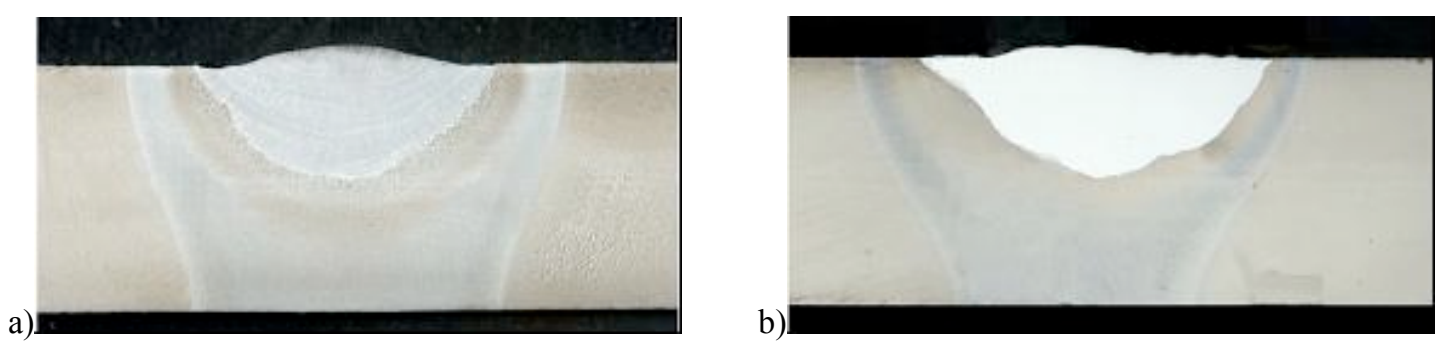

Figure 1: Macrographs through the $12 \mathrm{~mm}$ thick welded plates made with a) OK75.78 and b) LTTE weld filler metal. 


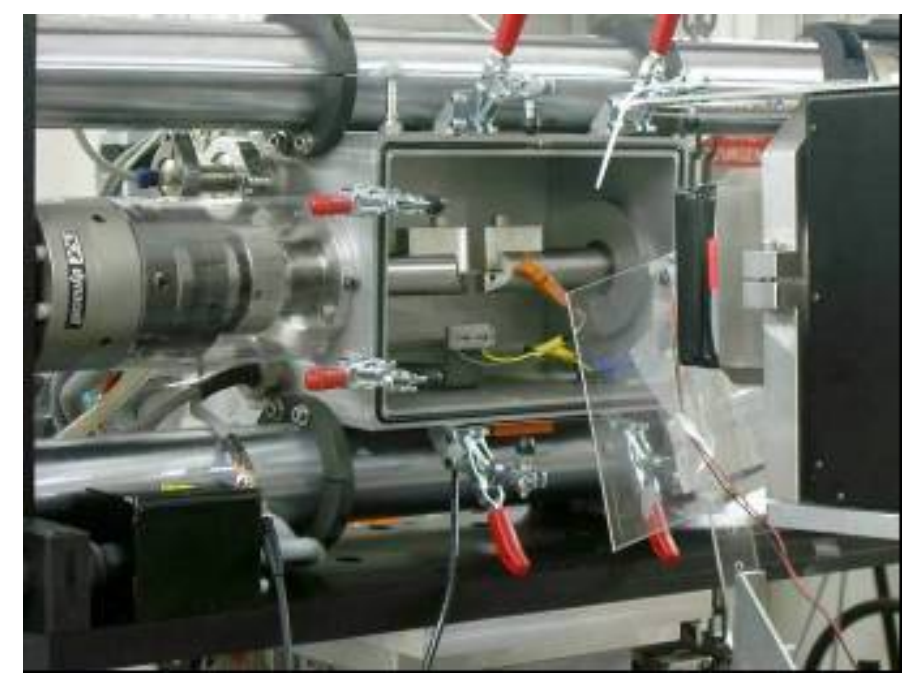

Figure 2: Photograph of the Electro-Thermal Mechanical Test rig on the ID11 beam line at the ESRF facility in Grenoble, France. The sample environmental chamber is photon transparent so that X-rays can pass through the back of the chamber (from behind the rig on the left hand side), and then pass through the sample gauge volume before reaching the detector which can be seen on the right-hand side. 


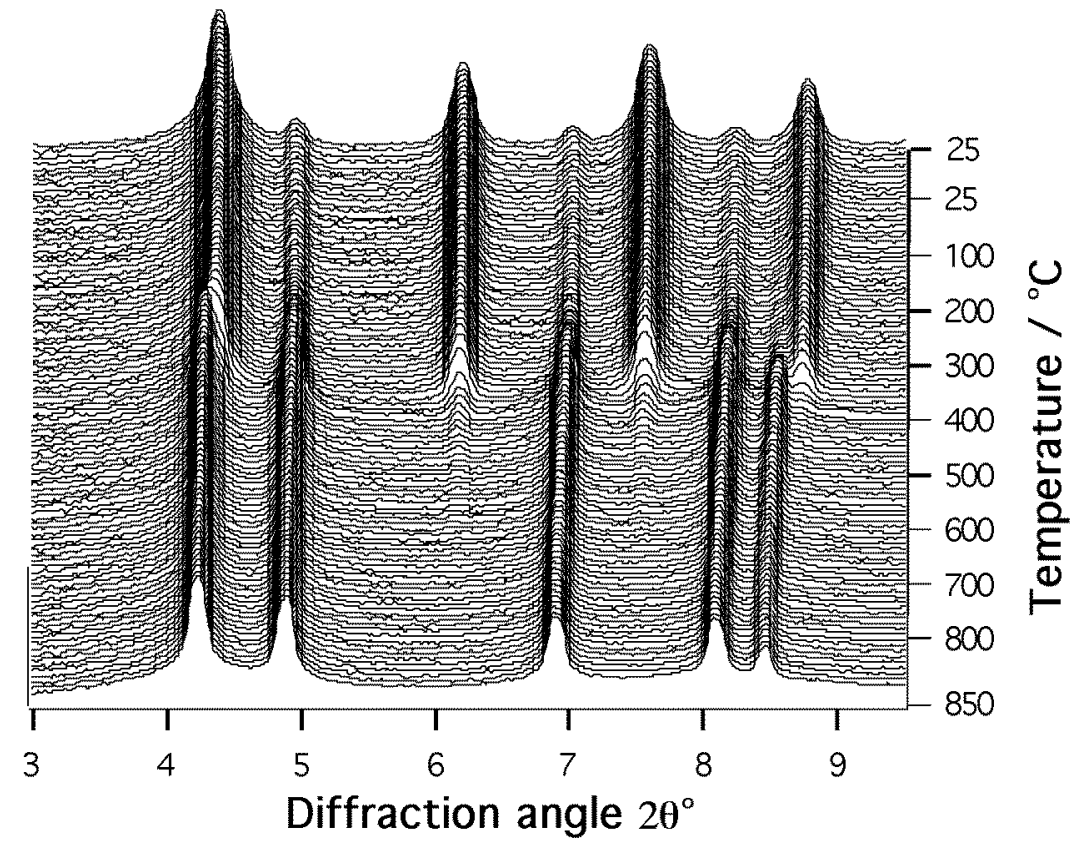

Figure 3: Transformation of weld filler metal OK75.78 from austenite to ferrite during cooling at $10^{\circ} \mathrm{C} \mathrm{s}^{-1}$. Intensity is displayed on a logarithmic scale. For clarity, every $5^{\text {th }}$ data set is shown. 


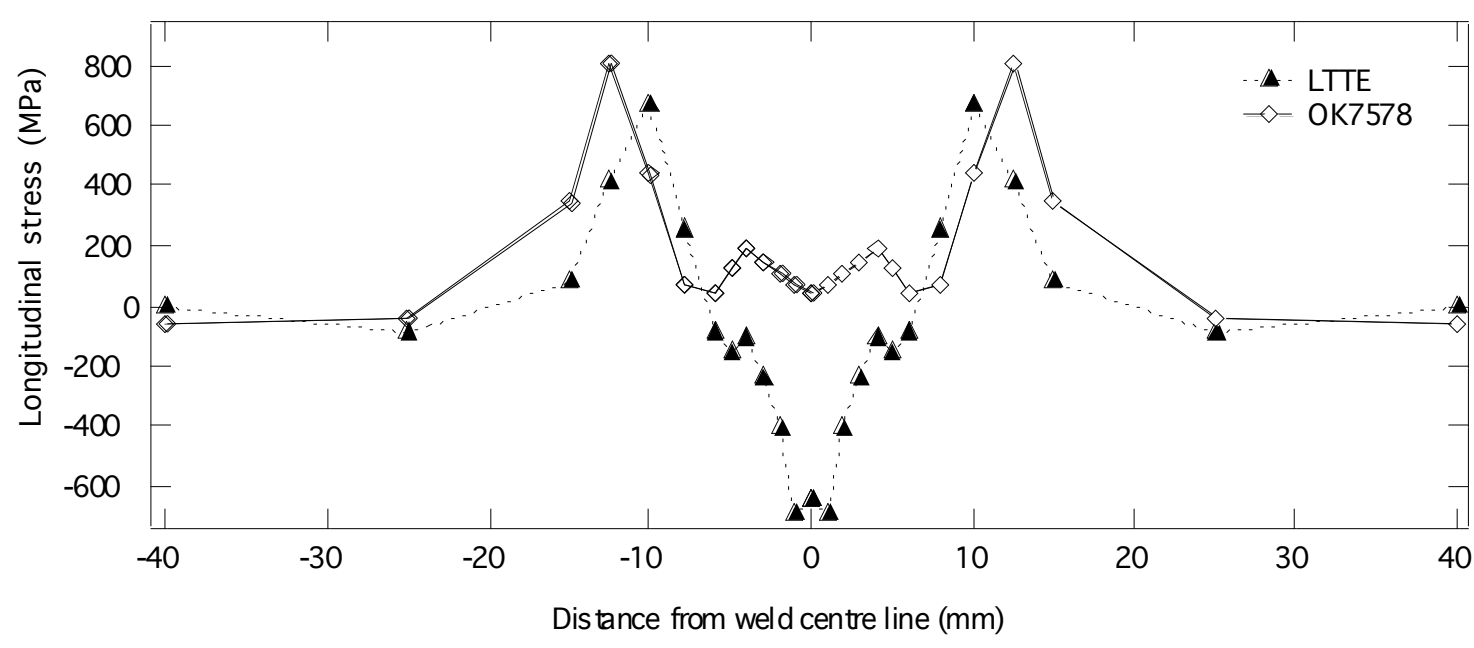

Figure 4: Longitudinal stress measured by neutron diffraction at Chalk River [10] as a function of distance from the weld centerline at a depth of $2.5 \mathrm{~mm}$. The HAZ extends laterally from between 11 $\mathrm{mm}$ at the top of the weld to $6 \mathrm{~mm}$ at the bottom on either side (Fig. 1). Neutron diffraction measurements on either side of the weld have been averaged. 


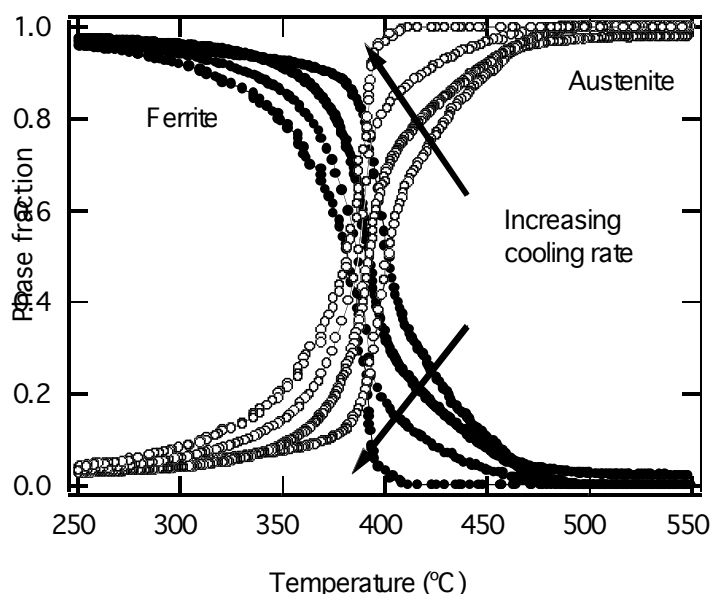

Figure 5: Austenite and ferrite phase fractions for OK75.78 as a function of temperature and cooling rates $\left(100,10,1\right.$ and $\left.0.1 \mathrm{C} \mathrm{s}^{-1}\right)$. 


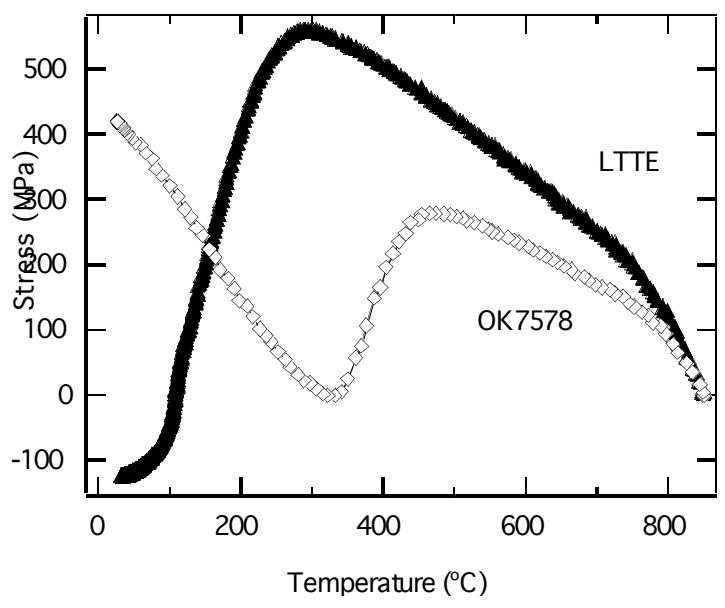

Figure 6: Results of Satoh tests on LTTE and OK75.78 weld filler metals cooling from $900{ }^{\circ} \mathrm{C}$ at $10^{\circ} \mathrm{C} \mathrm{s}^{-1}$ [10]. 

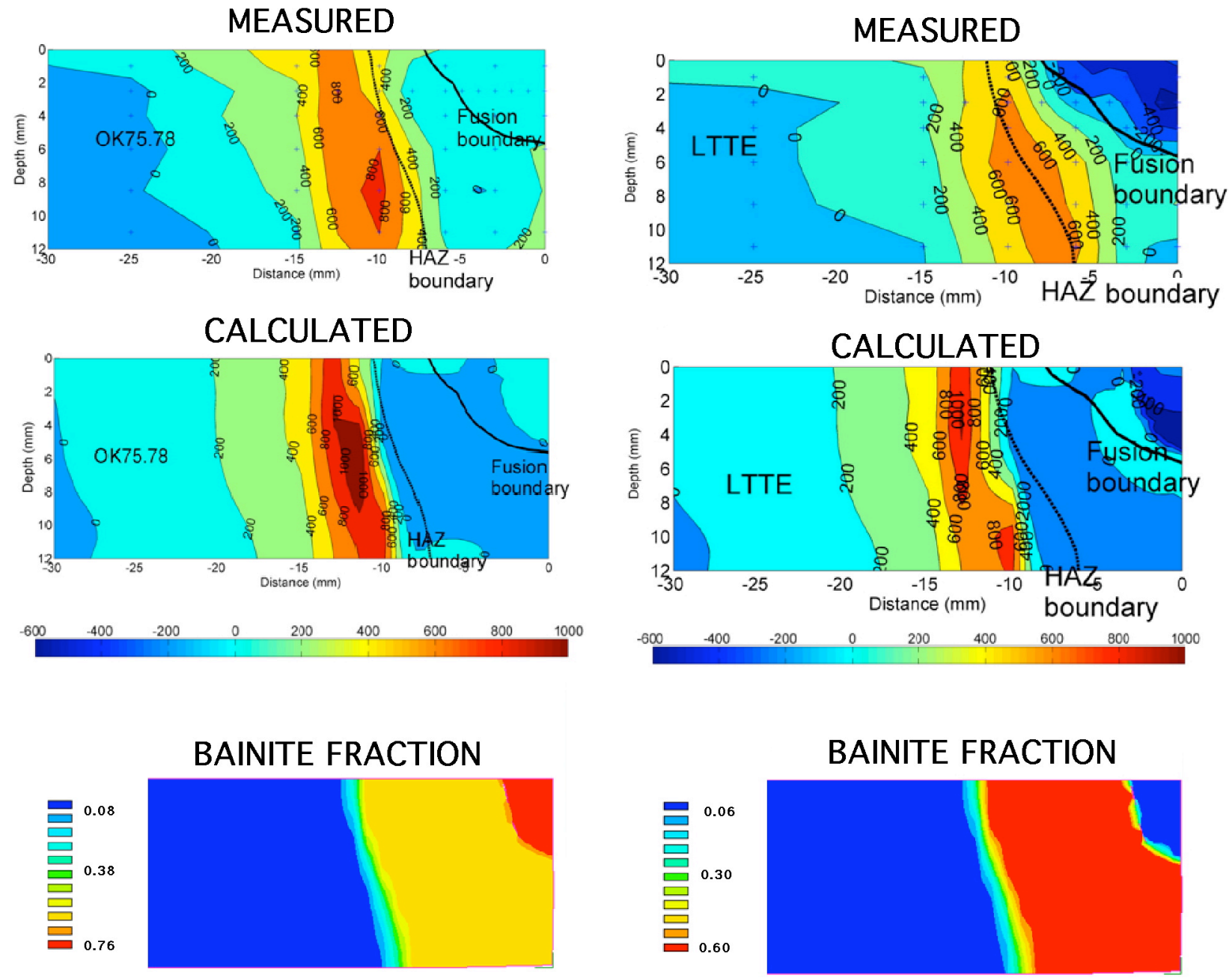

Figure 7: Comparison of neutron diffraction measurements of longitudinal residual stress (top) in the near weld region as reported in Ref. [10] with the stress distributions predicted by SYSWELD (middle) for welds made using the OK75.78 filler metal (left) and the LTTE filler metal (right). The predicted proportions of bainite formed as a consequence of welding appear for each weld at the bottom of the figure. All dimensions are in $\mathrm{mm}$ and all stresses are in $\mathrm{MPa}$. 
Table 1: Approximate compositions of base plate and filler metals in wt $\%$.

\begin{tabular}{|c|c|c|c|c|c|c|c|}
\hline Material & $\mathbf{C}$ & $\mathbf{S i}$ & $\mathbf{M n}$ & $\mathbf{C r}$ & $\mathbf{~ N i}$ & $\mathbf{M o}$ & $\mathbf{C u}$ \\
\hline Weldox 960 & 0.20 & 0.50 & 1.6 & 0.7 & 2.0 & 0.7 & 0.3 \\
\hline OK 75.78 & 0.05 & 0.19 & 2.0 & 0.4 & 3.1 & 0.6 & - \\
\hline LTTE & 0.07 & 0.20 & 1.3 & 9.1 & 8.5 & - & - \\
\hline
\end{tabular}

